\title{
Association between a restriction fragment length polymorphism at the liver/islet cell (GluT 2) glucose transporter and familial Type 2 (non-insulin-dependent) diabetes mellitus
}

\author{
J. C.Alcolado*, M. G. Baroni and S. R. Li \\ St. Bartholomew's Hospital, London, UK
}

\begin{abstract}
Summary. Patients with Type 2 (non-insulin-dependent) diabetes mellitus and a strong family history of the disease may represent a sub-group where genetic factors play a preeminent role in transmission of the disease. A defect in the liver/islet cell glucose transporter (GluT 2) could explain many of the pathophysiological features of the disease. In order to test the hypothesis that genetic variation at the GluT 2 locus contributes genetic susceptibility to Type 2 diabetes, 60 unrelated Caucasian diabetic patients with at least one affected sibling were genotyped for a Taq 1 restriction fragment length polymorphism marker. Hybridisation with a cDNA GluT 2 probe identified two alleles of sizes 13 kilobase (T1) and 19 kilobase (T2). The allele frequencies in the diabetic group with a family history were significantly
\end{abstract}

different from those in a racially-matched control population of 122 subjects with no personal or family history of the disease (diabetic patients $\mathrm{T} 1=0.96, \mathrm{~T} 2=0.04$, control subjects $\mathrm{T} 1=0.89, \mathrm{~T} 2=0.11, p<0.03)$. However, when the study was repeated with 54 diabetic patients with indeterminate family history, statistical significance was not reached although the allele frequencies showed a similar trend. The findings of this study support the hypothesis that a genetic variant of the liver/islet cell glucose transporter may contribute to familial susceptibility in Type 2 diabetes.

Key words: Genetics, diabetes mellitus, restriction fragment length polymorphism, glucose-transport, familial.
A strong familial predisposition to Type 2 (non-insulindependent) diabetes mellitus has been demonstrated in numerous studies. Approximately $30 \%$ of Caucasian subjects with the disease have an affected first degree relative and siblings are affected in up to $10 \%$ of cases [1]. Twin studies have confirmed that genetic rather than environmental factors are paramount [2]. However, the search for genetic markers in Type 2 diabetes has proved less rewarding than in Type 1 (insulin-dependent) diabetes.

In recent years restriction fragment length polymorphism (RFLP) markers have been sought around genes which could contribute susceptibility to Type 2 diabetes. The candidate genes studied have included the insulin gene [3], insulin receptor gene [4] and the GluT 1 and GluT 4 glucose transporter genes [5,6]. A defect in the recently characterised liver/pancreatic islet cell glucose transporter (GluT 2) protein could explain many of the pathophysiological features of Type 2 diabetes [7].

* R. D. Lawrence Fellow of the British Diabetic Association
One approach has been to genotype a diabetic population and to compare the frequency of RFLP alleles with that in a control group. Previous studies have relied on racially distinct diabetic populations excluding those patients that could not be unequivocally designated as Type 2 diabetic patients. It has been suggested that a more homogeneous population may be achieved by selecting only obese Type 2 diabetic patients. However, until now no effort has been made to select only those patients with a strong family history for the disease in a population study. An association between an RFLP allele and Type 2 diabetes can only be demonstrated when that particular allele is in linkage disequilibrium with a genetic variant contributing to disease susceptibility. $\mathrm{Pa}$ tients with a strong family history of Type 2 diabetes may represent a distinct sub-set with a well-defined genetic contribution. Patients without a family history of the disease may represent a more diverse group including those where environmental rather than genetic factors are more important.

In this study we have examined the association of an RFLP marker around the GluT 2 gene in subjects with Type 2 diabetes and a strong family history of the disease. 


\section{Subjects and methods}

British Caucasian patients with Type 2 diabetes attending clinics at St.Bartholomew's Hospital, London and Addenbrooke's Hospital, Cambridge were questioned regarding family history of Type 2 diabetes. Those with at least one affected sibling were invited to participate in the study. A total of 60 subjects ( 29 female) were recruited with an age range $43-86$ years (mean 58 years). The mean body mass index (BMI) was $24.3 \mathrm{~kg} / \mathrm{m}^{2}$ (range $21.0-26.2 \mathrm{~kg} / \mathrm{m}$ ). All patients had been diagnosed after the age of 30 years (mean age of diagnosis 48 years) and met current World Health Organisation guidelines. Insulin treatment in four of the patients had been preceded by at least 5 years' therapy with oral hypoglycaemic agents and there was no history of ketoacidotic events. It was possible to personally interview surviving relatives of 35 of the patients. In all cases the relatives had been correctly described as suffering from Type 2 diabetes.

In addition a further 54 patients with Type 2 diabetes for whom detailed family history was not available were recruited to the study. The mean age of this group was 56 years (range 38-78 years) with a mean BMI of $24.2 \mathrm{~kg} / \mathrm{m}^{2}$. The mean duration of diabetes was 8 years. Control subjects $(122,68$ female) were selected from non-diabetic Caucasian patients attending hospital out-patient clinics. The mean age of the control group was 52 years and the mean BMI $23.6 \mathrm{~kg} / \mathrm{m}^{2}$. Subjects were excluded if there was a personal or family history of diabetes or cardiovascular disease or a random blood glucose level about $7.0 \mathrm{mmol} / \mathrm{l}$.

Between 10 and $20 \mathrm{ml}$ of whole blood was taken from all subjects after informed consent had been obtained. DNA was extracted from lymphocytes by standard methods. Aliquots of DNA $(8 \mu \mathrm{l})$ were digested with the restriction enzyme Taq 1 according to the manufacturer's instructions (Gibco, Paisley, UK) and fragments separated on $0.85 \%$ agarose gels by electrophoresis followed by transfer to nylon membranes by Southern blotting. Membranes were prehybridised with herring sperm DNA prior to hybridisation for $48 \mathrm{~h}$ with a $32 \mathrm{p}$ labelled GluT 2 probe. Membranes were then washed to $0.2 \%$ saline sodium citrate (SSC) stringency at $64^{\circ} \mathrm{C}$ and bands visualised by autoradiography using Hyperfilm HP film within intensifying screens for 5 days.

The GluT 2 probe was kindly made available by Dr. G. Bell, Howard Hughes Institute, Chicago, Ill., USA. The probe PSPGT-2 hybridises with the entire cDNA sequence and in addition 10 base pairs at the $5^{\prime}$ end and 900 base pairs at the $3^{\prime}$ end of the genomic region.

\section{Statistical analysis}

The null hypothesis was that there was no difference in allele frequencies between diabetic patients and control subjects. This was tested by recourse to Chi Square testing using the Minitab statistical package.

\section{Results}

Autoradiography revealed two polymorphic Taq 1 sites. All samples had bands corresponding to alleles of size 19 kilobases (kb) (T1), $13 \mathrm{~kb}$ (T2) or both. These alleles correspond to the Taq 1a polymorphism reported by Matsutani et al. [8]. A fragment of size $7.2 \mathrm{~kb}$ (allele T3) was detected in all samples possessing the T1 allele. In addition a fragment of size $3.5 \mathrm{~kb}$ (T4 allele) occurred in all but one sample. The T1/T2 and T3/T4 systems are therefore in virtual $100 \%$ disequilibrium.

In the control group, $11 \%$ of samples showed fragments of $19.0 \mathrm{~kb}$ or $7.2 \mathrm{~kb}$ (T1 and T3 alleles). However, only $4 \%$ of subjects in the diabetic group with affected siblings had these extra bands (Table 1 and 2). This result
Table 1. Genotypes of subjects with respect to the T1/T2 system

\begin{tabular}{lccc}
\hline Subjects & T1 T1 & T1 T2 & T2 \\
\hline $\begin{array}{l}\text { Diabetic patients with } \\
\text { affected siblings }\end{array}$ & 1 & 3 & 56 \\
$\begin{array}{l}\text { Diabetic patients } \\
\text { indeterminate family }\end{array}$ & & & \\
history & 1 & 5 & 48 \\
Control subjects & 0 & 28 & 94 \\
\hline
\end{tabular}

Table 2. Allele frequencies of the $\mathrm{T} 1 / \mathrm{T} 2$ system

\begin{tabular}{lll}
\hline Subjects & $\mathrm{T} 1$ & $\mathrm{~T} 2$ \\
\hline $\begin{array}{l}\text { Diabetic patients with } \\
\text { affected siblings }\end{array}$ & 5 & 115 \\
$\begin{array}{l}\text { Diabetic patients } \\
\text { indeterminate } \\
\text { family history }\end{array}$ & $(0.04)$ & $(0.96)^{\mathrm{a}}$ \\
Control subjects & 7 & 101 \\
\hline
\end{tabular}

a Chi square $=5.21, p<0.03 ;{ }^{\mathrm{b}}$ Chi square $=2.09, p \mathrm{NS}$

was statistically significant $(\mathrm{Chi}=5.21, z=4.694 p<0.03)$. However, there was no statistical significance between allele frequencies in the group of diabetic patients with indeterminate family history and the control population. The control group genotypes were in Hardy Weinberg equilibrium.

\section{Discussion}

This study has demonstrated a significant difference between the presence of restriction length fragments around the GluT 2 gene in diabetic subjects with a strong family history and a non-diabetic control group.

The T1/T2 RFLP reported in this study corresponds to the Taq 1a polymorphism described in the American Black population by Matsutani et al. [8]. However, the polymorphism could not be detected amongst Matsutani's American Caucasians. Our results show that this RFLP is found in British Caucasians but that the low frequency of the $\mathrm{T} 1$ allele will require many more than the 11 American whites originally studied by Matsutani to be screened for its detection. The second Taq 1 polymorphism found in the present study does not correspond to the Taq $1 \mathrm{~b}$ RFLP described by Matsutani and this is probably a result of the different probes employed. There appears to be virtually complete linkage disequilibrium between the two RFLPS in British Caucasians in that only one subject (in the control group) had a different genotype in the T1/T2 system than the T3/T4 system.

Approximately $30 \%$ of British patients with Type 2 diabetes have an affected first degree relative and only $10 \%$ will have an affected sibling. If a genetic marker is only associated with the disease in patients with a strong family history, then the association may not reach statistical significance if an unselected group is used in a population association study.

The group of diabetic patients collected without regard to family history may be considered broadly similar to 
those used in previous population association studies where the importance of family history was not considered. An attempt to define family history in the indeterminate group relying upon hospital notes revealed 13 patients with documented affected first degree relatives. It is of interest that all these patients had the T2T2 genotype and therefore showed the same allele trend as the group with affected siblings. However, the numbers are too small to attain significance and retrospective studies of this sort are liable to ascertainment bias. The low frequency of the $\mathrm{T} 1$ allele together with the relatively small numbers in each group of diabetic patients may explain why statistical significance is not reached when comparing allele frequencies between the two groups of diabetic patients.

The limitations of population association studies have been discussed elsewhere [9]. Positive results are best treated as preliminary pointers to specific genetic influences. The results of this present study are at the borderline of statistical significance. Only by intra- and trans-racial replication by different laboratories will important associations become established.

The use of an affected member pedigree analysis [10] to elucidate the importance of genetic variants of Glu'T 2 in Type 2 diabetes may lend further support to the results of this population association study. Such an analysis awaits the definition of highly polymorphic markers around this site which are required to circumvent the problems of collecting large families in a disease of late onset.

In recent years the molecular basis of many previously enigmatic monogenic diseases have been elucidated. The rate of progress in the polygenic diseases such as Type 2 diabetes has been slower. This preliminary report firmly directs future study to the molecular biology of the liver/islet cell (GluT 2) glucose transporter.

Acknowledgements. We wish to thank the British Diabetic Association for funding JCA and SRL and the Accademia Nazionale dei
Lincei/Royal Society for funding MGB. The cDNA GluT 2 probe was kindly made available by Dr. G. Bell. We also wish to thank Dr. $\mathrm{R}$. Oelbaum for helping in patient recruitment, and preparing some of the DNA.

\section{References}

1. Alcolado JC, Alcolado R (1991) Importance of maternal history of non-insulin dependent diabetic patients. Br Med J 302: 11781180

2. Barnett AH, Eff C, Leslie RDG, Pyke DA (1981) Diabetes in identical twins - a study of 200 pairs. Diabetologia 20: 87-93

3. Bell GI, Kayano T, Buse JB et al. (1990) Molecular biology of mammalian glucose transporters. Diab Care 13: 198-216

4. Elbein SC, Corsetti L, Goldgar D, Skolnick M, Permutt A (1988) Insulin gene in familial NIDDM. Lack of linkage in Utah Mormon pedigrees. Diabetes 37:569-576

5. McClain DA, Henry RR, Ullich A, Olefsky JM (1989) Restriction fragment length polymorphism in insulin receptor gene and insulin resistance in NIDDM. Diabetes 37: 1071-1075

6. Li SR, Baroni MG, Oelbaum RS, Stocks J, Galton DJ (1988) Association of genetic variant of the glucose transporter with noninsulin-dependent diabetes mellitus. Lancet: $368-370$

7. Oelbaum RS, Li SR, Baroni MG, Stocks J, Alcolado JC, Galton DJ (1990) Polymorphisms of glucose transporter genes in Type 2 diabetes. Diabetologia 33 [Suppl]: All (Abstract)

8. Matsutani A, Koranyi L, Cox N, Permutt MA (1990) Polymorphisms of GLUT 2 and GLUT 4 genes. Use in evaluation of genetic susceptibility to NIDDM in Blacks. Diabetes 39: 1534 1542

9. Cox NJ, Bell GI (1989) Disease associations, chance, artifact or susceptibility genes? Diabetes 38: 947-950

10. Weeks DE, Lange K (1988) The affected pedigree method of linkage analysis. Am J Hum Genet 42: 315-326

Received: 22 April 1991

and in revised form: 24 June 1991

Dr. J.C. Alcolado

Diabetic Unit

East Birmingham Hospital

Bordesley Green East

Birmingham

UK 